\title{
A coupled coincidence point theorem in partially ordered metric spaces with an implicit relation
}

\author{
Selma Gülyaz ${ }^{1}$, Erdal Karapınar ${ }^{2 *}$ and Illker Savas Yüce ${ }^{3}$
}

"Correspondence:

erdalkarapinar@yahoo.com; ekarapinar@atilim.edu.tr

${ }^{2}$ Department of Mathematics, Atilim University, İncek, Ankara 06836, Turkey

Full list of author information is available at the end of the article

\begin{abstract}
In this manuscript, we discuss the existence of a coupled coincidence point for mappings $F: X \times X \rightarrow X$ and $g: X \rightarrow X$, where $F$ has the mixed $g$-monotone property, in the context of partially ordered metric spaces with an implicit relation. Our main theorem improves and extends various results in the literature. We also state some examples to illustrate our work.

MSC: $47 \mathrm{H} 10 ; 54 \mathrm{H} 25 ; 46 \mathrm{~J} 10 ; 46 \mathrm{~J} 15$

Keywords: coupled coincidence point; coupled fixed point; mixed monotone property; implicit relation; ordered partial metric space; O-compatible
\end{abstract}

\section{Introduction and preliminaries}

It is well known that fixed point theory is one of the crucial and very efficient tools in nonlinear functional analysis. This is because its ever-growing use in this field is very extensive in applications. In particular, the effects of fixed point theory are most apparent in fields like economy, computer sciences and engineering including many branches of mathematics. Historically, in 1886, Poincaré initiated first fixed point results. Then, in 1912, Brouwer published a result in this field, which was equivalent to Poincaré's theorem, which in the simplest terms states that a continuous function from a disk D to itself has a fixed point. But most of the substantial advances in fixed point theory started after the celebrated fixed point result of Banach, known as Banach's contraction mapping principle, in 1922. This principle can be stated as follows: any contraction in a complete metric space has a unique fixed point. When compared to Browder's fixed point theorem, the power of Banach's principle comes from the fact that it guarantees the uniqueness of a fixed point and gives a method to determine the fixed point. These two strengths of Banach's contraction mapping principle have attracted attention of many prominent mathematicians who aim to broaden the applications of nonlinear functional analysis via fixed point theory in various quantitative sciences.

In the light of these developments, Guo and Lakshmikantham [1] defined the notion of a coupled fixed point in 1987. Later, Gnana-Bhaskar and Lakshmikantham [2] improved the idea of a coupled fixed point in the category of partially ordered metric spaces by introducing the notion of a mixed monotone mapping and presented certain applications on the solution of periodic boundary value problems. Interested readers may refer to [3- 
5] and the references therein to follow the development of fixed point theory on partially ordered metric spaces.

For the sake of completeness, we will review the basic definitions and fundamental results.

Definition 1 (See [2]) Let $(X, \preceq$ ) be a partially ordered set and $F: X \times X \rightarrow X$. The mapping $F$ is said to have the mixed monotone property if $F(x, y)$ is monotone non-decreasing in $x$ and is monotone non-increasing in $y$, that is, for any $x, y \in X$,

$$
x_{1}, x_{2} \in X, \quad x_{1} \preceq x_{2} \quad \Rightarrow \quad F\left(x_{1}, y\right) \preceq F\left(x_{2}, y\right)
$$

and

$$
y_{1}, y_{2} \in X, \quad y_{1} \preceq y_{2} \quad \Rightarrow \quad F\left(x, y_{1}\right) \succeq F\left(x, y_{2}\right) .
$$

Definition 2 (See [2]) An element $(x, y) \in X \times X$ is called a coupled fixed point of the mapping $F: X \times X \rightarrow X$ if

$$
x=F(x, y) \quad \text { and } \quad y=F(y, x) .
$$

We state now the main results of Gnana-Bhaskar and Lakshmikantham in [2].

Theorem 3 (See [2]) Let $(X, \preceq)$ be a partially ordered set and suppose there exists a metric $d$ on $X$ such that $(X, d)$ is a complete metric space. Assume that there exists a $k \in[0,1)$ with

$$
d(F(x, y), F(u, v)) \leq \frac{k}{2}[d(x, u)+d(y, v)]
$$

for all $x \succeq u$ and $y \preceq v$. Let either

(a) $F: X \times X \rightarrow X$ be a continuous mapping having the mixed monotone property on $X$, or

(b) X have the following property:

(i) if a non-decreasing sequence $\left\{x_{n}\right\} \rightarrow x$, then $x_{n} \preceq x$ for all $n$,

(ii) if a non-increasing sequence $\left\{y_{n}\right\} \rightarrow y$, then $y \preceq y_{n}$ for all $n$.

If there exist two elements $x_{0}, y_{0} \in X$ with

$$
x_{0} \preceq F\left(x_{0}, y_{0}\right) \quad \text { and } \quad y_{0} \succeq F\left(y_{0}, x_{0}\right) \text {, }
$$

then there exist $x, y \in X$ such that

$$
x=F(x, y) \text { and } y=F(y, x) .
$$

Following this theorem, several coupled coincidence/fixed point theorems and their applications to integral equations, matrix equations and a periodic boundary value problem have been reported (see, e.g., [6-19] and references therein). In particular, Lakshmikantham and Cirić [6] established coupled coincidence and coupled fixed point theorems for two mappings $F: X \times X \rightarrow X$ and $g: X \rightarrow X$, where $F$ has the mixed $g$-monotone property and the functions $F$ and $g$ commute, as an extension of the fixed point results in [2]. For the sake of completeness, we recall these characterizations. 
Definition 4 (See [6]) Let $(X, \preceq)$ be a partially ordered set and let $F: X \times X \rightarrow X$ and $g: X \rightarrow X$ be two mappings. We say $F$ has the mixed $g$-monotone property if $F(x, y)$ is $g$ non-decreasing in its first argument and is $g$-non-increasing in its second argument, that is, for any $x, y \in X$,

$$
x_{1}, x_{2} \in X, \quad g x_{1} \preceq g x_{2} \quad \Rightarrow \quad F\left(x_{1}, y\right) \preceq F\left(x_{2}, y\right)
$$

and

$$
y_{1}, y_{2} \in X, \quad g y_{1} \preceq g y_{2} \quad \Rightarrow \quad F\left(x, y_{1}\right) \succeq F\left(x, y_{2}\right) .
$$

Definition 5 (See [6]) An element $(x, y) \in X \times X$ is called a coupled coincident point of the mappings $F: X \times X \rightarrow X$ and $g: X \rightarrow X$ if

$$
g x=F(x, y) \quad \text { and } \quad g y=F(y, x) .
$$

Definition 6 [7] The mappings $F$ and $g$, where $F: X \times X \rightarrow X, g: X \rightarrow X$, are said to be compatible if

$$
\lim _{n \rightarrow \infty} d\left(g F\left(x_{n}, y_{n}\right), F\left(g x_{n}, g y_{n}\right)\right)=0
$$

and

$$
\lim _{n \rightarrow \infty} d\left(g F\left(y_{n}, x_{n}\right), F\left(g y_{n}, g x_{n}\right)\right)=0,
$$

where $\left\{x_{n}\right\}$ and $\left\{y_{n}\right\}$ are sequences in $X$ such that $F\left(x_{n}, y_{n}\right)=g x_{n} \rightarrow x$ and $F\left(y_{n}, x_{n}\right)=g y_{n} \rightarrow$ $y$ as $n \rightarrow \infty$ for all $x, y \in X$ are satisfied.

Definition 7 (See [20]) Two self-mappings $A$ and $B$ are said to be weakly compatible if they commute at their coincidence points, i.e., $A B u=B A u$ whenever $A u=B u, u \in X$.

Choudhury and Kundu in [7] defined the notion of compatibility and showed the result established in [6] with a different set of conditions. In other words, the authors constructed their result by assuming that $F$ and $g$ are compatible mappings. Later, Luong and Thuan [13] slightly improved the notion of compatible mappings on partially ordered metric spaces, namely $O$-compatible mappings. In this paper [13], the authors proved some coupled coincidence point theorems for $O$-compatible type mappings in the context of partially ordered generalized metric spaces.

We recall the concept of $O$-compatible mappings as follows.

Definition 8 ( $c f$. [13]) Let $(X, \preceq, d)$ be a partially ordered metric space. Two mappings $F: X \times X \rightarrow X$ and $g: X \rightarrow X$ are said to be $O$-compatible if

$$
\lim _{n \rightarrow \infty} d\left(g F\left(x_{n}, y_{n}\right), F\left(g x_{n}, g y_{n}\right)\right)=0
$$

and

$$
\lim _{n \rightarrow \infty} d\left(g F\left(y_{n}, x_{n}\right), F\left(g y_{n}, g x_{n}\right)\right)=0,
$$


where $\left\{x_{n}\right\}$ and $\left\{y_{n}\right\}$ are sequences in $X$ such that $\left\{g x_{n}\right\},\left\{g y_{n}\right\}$ are monotone and

$$
\lim _{n \rightarrow \infty} F\left(x_{n}, y_{n}\right)=\lim _{n \rightarrow \infty} g x_{n}=x
$$

and

$$
\lim _{n \rightarrow \infty} F\left(y_{n}, x_{n}\right)=\lim _{n \rightarrow \infty} g y_{n}=y
$$

are satisfied for some $x, y \in X$.

Let $(X, \preceq, d)$ be a partially ordered metric space. If $F: X \times X \rightarrow X$ and $g: X \rightarrow X$ are compatible, then they are $O$-compatible. However, the converse is not true. The following example shows that there exist mappings which are $O$-compatible but not compatible.

Example 9 Let $X=\{0\} \cup[1 / 2,2]$ with the usual metric $d(x, y)=|x-y|$ for all $x, y \in X$. We consider the following order relation on $X$ :

$$
x, y \in X, \quad x \preceq y \quad \Leftrightarrow \quad x=y \quad \text { or } \quad(x, y) \in\{(0,0),(0,1),(1,1)\} .
$$

Let $F: X \times X \rightarrow X$ be given by

$$
F(x, y)= \begin{cases}0 & \text { if } x, y \in\{0\} \cup[1 / 2,1] \\ 1 & \text { otherwise }\end{cases}
$$

and $g: X \rightarrow X$ be defined by

$$
g x= \begin{cases}0 & \text { if } x=0 \\ 1 & \text { if } 1 / 2 \leq x \leq 1 \\ \frac{2 a-1-x}{2(a-1)} & \text { if } 1<x \leq a \\ \frac{1}{2} & \text { if } a<x \leq 2\end{cases}
$$

Then $F$ and $g$ are $O$-compatible but not compatible. To discern this, let $\left\{x_{n}\right\}$ and $\left\{y_{n}\right\}$ be two sequences in $X$ such that $\left\{g x_{n}\right\}$ and $\left\{g y_{n}\right\}$ are monotone and

$$
\lim _{n \rightarrow \infty} F\left(x_{n}, y_{n}\right)=\lim _{n \rightarrow \infty} g x_{n}=x
$$

and

$$
\lim _{n \rightarrow \infty} F\left(y_{n}, x_{n}\right)=\lim _{n \rightarrow \infty} g y_{n}=y
$$

for some $x, y \in X$. It is easy to see that $x=y \in\{0,1\}$ since $F\left(x_{n}, y_{n}\right)=F\left(y_{n}, x_{n}\right) \in\{0,1\}$. It is not possible to have $x=y=1$. Assume otherwise. There exists a positive integer $N$ such that $g x_{n}=1$ and $g y_{n}=1$ for all $n>N$, since both $g x_{n}$ and $g y_{n}$ are monotone. Then we have $x_{n}, y_{n} \in[1 / 2,1]$ for all $n>N$, which implies that $F\left(x_{n}, y_{n}\right)=0$ and $F\left(y_{n}, x_{n}\right)=0$ for all $n>N$, a contradiction. Thus, $x=y=0$. In this case, we derive that $g x_{n}=0$ and $g y_{n}=0$ for all $n>M$ 
for some positive integer $M$. Then, we get $x_{n}=0$ and $y_{n}=0$ for all $n>M$. As a result, we obtain

$$
\lim _{n \rightarrow \infty} d\left(g F\left(x_{n}, y_{n}\right), F\left(g x_{n}, g y_{n}\right)\right)=0, \quad \lim _{n \rightarrow \infty} d\left(g F\left(y_{n}, x_{n}\right), F\left(g y_{n}, g x_{n}\right)\right)=0,
$$

$d\left(g F\left(x_{n}, y_{n}\right), F\left(g x_{n}, g y_{n}\right)\right)=0$, and $d\left(g F\left(y_{n}, x_{n}\right), F\left(g y_{n}, g x_{n}\right)\right)=0$. Therefore, $F$ and $g$ are $O$ compatible.

On the other hand, let

$$
x_{n}=1+\frac{2(a-1)}{(n+1)} \quad \text { and } \quad y_{n}=1+\frac{2(a-1)}{(n+1)}
$$

for $n=1,2,3, \ldots$. Observe that

$$
F\left(x_{n}, y_{n}\right)=F\left(1+\frac{2(a-1)}{(n+1)}, 1+\frac{2(a-1)}{(n+1)}\right)=1 \rightarrow 1
$$

and

$$
g x_{n}=g\left(1+\frac{2(a-1)}{(n+1)}\right)=1-\frac{1}{n+1} \rightarrow 1
$$

as $n$ approaches to $\infty$, where $F\left(y_{n}, x_{n}\right)=F\left(x_{n}, y_{n}\right)$ and $g x_{n}=g y_{n}$. But we have

$$
d\left(g F\left(x_{n}, y_{n}\right), F\left(g x_{n}, g y_{n}\right)\right)=d\left(F\left(1-\frac{1}{n+1}, 1-\frac{1}{n+1}\right), g 1\right)=d(0,1)=1
$$

which does not approach to 0 as $n$ approaches to $\infty$. Hence, $F$ and $g$ are not compatible.

Remark 10 In Example 9, if we let $a=3 / 2$, we obtain the example presented in [13].

In nonlinear analysis, especially in fixed point theory, implicit relations on metric spaces have been investigated heavily in many articles (see, e.g., [21-24] and references therein). In this paper, by using the following implicit relation, we examine the existence of a coupled coincidence point theorem for mappings $F: X \times X \rightarrow X$ and $g: X \rightarrow X$ in the context of a partial metric space, where $F$ has the mixed $g$-monotone property and $F, g$ are O-compatible.

Let $\mathbb{R}_{+}$denote the set of all nonnegative real numbers. Also, let $\Phi$ denote the collection of all functions $\varphi: \mathbb{R}_{+} \rightarrow \mathbb{R}_{+}$which satisfy

(i) $\varphi$ is continuous and non-decreasing,

(ii) $\varphi(t)<t$ for each $t>0$ and $\varphi(0)=0$.

We reserve $\mathbb{H}$ for the class of all continuous functions $H: \mathbb{R}_{+}^{6} \rightarrow \mathbb{R}$ satisfying

(H1) $H\left(t_{1}, t_{2}, t_{3}, t_{4}, t_{5}, t_{6}\right)$ is non-increasing in $t_{3}$ and $t_{6}$,

(H2) if $H(z, u, u+v, v, w, u+v) \leq 0$, then $z+u \leq h(v+w)$, where $h \in[0,1)$.

Example 11 The following functions lie in $\mathbb{H}$ :

- $H_{1}\left(t_{1}, t_{2}, t_{3}, t_{4}, t_{5}, t_{6}\right)=t_{1}+t_{2}-\alpha t_{3}-\beta t_{4}-\gamma t_{5}-\theta t_{6}$, where $\alpha, \beta, \gamma, \theta$ are nonnegative real numbers satisfying $\alpha+\beta+\gamma+\theta<1$.

- $H_{2}\left(t_{1}, t_{2}, t_{3}, t_{4}, t_{5}, t_{6}\right)=t_{1}-k\left\{t_{3}+t_{4}\right\}$, where $k \in\left(0, \frac{1}{2}\right)$. 
- $H_{3}\left(t_{1}, t_{2}, t_{3}, t_{4}, t_{5}, t_{6}\right)=t_{2}-k\left\{t_{3}+t_{4}\right\}$, where $k \in\left(0, \frac{1}{2}\right)$.

- $H_{4}\left(t_{1}, t_{2}, t_{3}, t_{4}, t_{5}, t_{6}\right)=t_{1}+t_{2}-h\left\{t_{3}+t_{4}\right\}$, where $h \in(0,1)$.

- $H_{5}\left(t_{1}, t_{2}, t_{3}, t_{4}, t_{5}, t_{6}\right)=t_{1}+t_{2}-\alpha\left(t_{4}+t_{5}\right)$, where $\alpha \in[0,1)$.

- $H_{6}\left(t_{1}, t_{2}, t_{3}, t_{4}, t_{5}, t_{6}\right)=t_{1}+t_{2}-\alpha t_{5}-\beta\left(t_{4}+t_{5}\right)-\gamma\left(t_{1}+t_{6}\right)$, where $\alpha, \beta, \gamma$ are nonnegative real numbers satisfying $\alpha+\beta+2 \gamma<1$.

- $H_{7}\left(t_{1}, t_{2}, t_{3}, t_{4}, t_{5}, t_{6}\right)=t_{1}+t_{2}-\alpha \max \left\{\frac{t_{3}}{2}, \frac{t_{4}+t_{5}}{2}, t_{4}+t_{5}-t_{2}\right\}$, where $\alpha \in[0,1)$.

In this paper, we prove a coupled coincidence point theorem for mappings satisfying such implicit relations.

\section{Main result}

We start by stating our primary theorem:

Theorem 12 Let $(X, d, \preceq)$ be a partially ordered complete metric space. Suppose that $F: X \times X \rightarrow X$ and $g: X \rightarrow X$ are two mappings such that $F$ has the mixed $g$-monotone property. Assume that there exists $H \in \mathbb{H}$ such that

$$
H\left(\begin{array}{c}
d(F(y, x), F(v, u)), d(F(x, y), F(u, v)), d(F(x, y), g x)+d(F(u, v), g u), \\
d(g x, g u), d(g y, g v), d(F(x, y), g u)+d(F(u, v), g x)
\end{array}\right) \leq 0
$$

for all $x, y, u, v \in X$ with $g x \succeq g u$ and $g y \preceq g v$. Suppose also that $F(X \times X) \subseteq g(X)$ and $g$ is continuous on $X$ and $O$-compatible with $F$. Additionally, suppose that either

(a) $F$ is continuous, or

(b) $X$ has the properties

(i) if a non-decreasing sequence $x_{n} \rightarrow x$, then $g x_{n} \preceq$ gx for all $n$, and

(ii) if a non-increasing sequence $y_{n} \rightarrow y$, then $g y \preceq g y_{n}$ for all $n$.

If there exist two elements $x_{0}, y_{0} \in X$ with

$$
g x_{0} \preceq F\left(x_{0}, y_{0}\right) \quad \text { and } \quad g y_{0} \succeq F\left(y_{0}, x_{0}\right) \text {, }
$$

then $F$ and $g$ have a coupled coincidence point in X.

Proof Let $x_{0}, y_{0} \in X$ be such that $g x_{0} \preceq F\left(x_{0}, y_{0}\right)$ and $g y_{0} \succeq F\left(y_{0}, x_{0}\right)$. We will construct the iterative sequences $\left\{x_{n}\right\}$ and $\left\{y_{n}\right\}$ in $X$ as follows:

$$
g x_{n+1}=F\left(x_{n}, y_{n}\right) \text { and } g y_{n+1}=F\left(y_{n}, x_{n}\right) \quad \text { for all } n \geq 0 \text {. }
$$

The sequences $\left\{x_{n}\right\}$ and $\left\{y_{n}\right\}$ are well defined since $F(X \times X) \subseteq g(X)$. Using the mathematical induction and the fact that $F$ has the mixed $g$-monotone property, we obtain

$$
g x_{n} \preceq g x_{n+1} \text { and } g y_{n} \succeq g y_{n+1}
$$

for all $n \geq 0$. If there is a number $n_{0} \in \mathbb{N}^{*}=\{0,1,2,3, \ldots\}$ such that $g x_{n_{0}}=g x_{n_{0}+1}$ and $g y_{n_{0}}=g y_{n_{0}+1}$, then $g x_{n_{0}}=g x_{n_{0}+1}=F\left(x_{n_{0}}, y_{n_{0}}\right)$ and $g y_{n_{0}}=g y_{n_{0}+1}=F\left(y_{n_{0}}, x_{n_{0}}\right)$. In this case, the theorem follows since $\left(x_{n_{0}}, y_{n_{0}}\right)$ is a coupled coincidence point of $F$ and $g$. 
Assume that $g x_{n} \neq g x_{n+1}$ or $g y_{n} \neq g y_{n+1}$ for all $n \in \mathbb{N}^{*}$. Since $g x_{n+1} \succeq g x_{n}$ and $g y_{n+1} \preceq g y_{n}$, we have

$$
H\left(\begin{array}{c}
d\left(F\left(y_{n+1}, x_{n+1}\right), F\left(y_{n}, x_{n}\right)\right), d\left(F\left(x_{n+1}, y_{n+1}\right), F\left(x_{n}, y_{n}\right)\right), \\
d\left(F\left(x_{n+1}, y_{n+1}\right), g x_{n+1}\right)+d\left(F\left(x_{n}, y_{n}\right), g x_{n}\right), d\left(g x_{n+1}, g x_{n}\right), \\
d\left(g y_{n+1}, g y_{n}\right), d\left(F\left(x_{n+1}, y_{n+1}\right), g x_{n}\right)+d\left(F\left(x_{n}, y_{n}\right), g x_{n+1}\right)
\end{array}\right) \leq 0
$$

by (2.1). Using the definitions of $\left\{x_{n}\right\}$ and $\left\{y_{n}\right\}$ in 2.2, we obtain

$$
H\left(\begin{array}{c}
d\left(g y_{n+2}, g y_{n+1}\right), d\left(g x_{n+2}, g x_{n+1}\right), d\left(g x_{n+2}, g x_{n+1}\right)+d\left(g x_{n+1}, g x_{n}\right), \\
d\left(g x_{n+1}, g x_{n}\right), d\left(g y_{n+1}, g y_{n}\right), d\left(g x_{n+2}, g x_{n}\right)
\end{array}\right) \leq 0 .
$$

By combining the property (H1) of $H$ with the triangle inequality, inequalities in (2.4) turn into

$$
H\left(\begin{array}{c}
d\left(g y_{n+2}, g y_{n+1}\right), d\left(g x_{n+2}, g x_{n+1}\right), d\left(g x_{n+2}, g x_{n+1}\right)+d\left(g x_{n+1}, g x_{n}\right), \\
d\left(g x_{n+1}, g x_{n}\right), d\left(g y_{n+1}, g y_{n}\right), d\left(g x_{n+2}, g x_{n+1}\right)+d\left(g x_{n+1}, g x_{n}\right)
\end{array}\right) \leq 0 .
$$

Then, the property (H2) of $H$ implies that

$$
d\left(g y_{n+2}, g y_{n+1}\right)+d\left(g x_{n+2}, g x_{n+1}\right) \leq h\left(d\left(g x_{n+1}, g x_{n}\right)+d\left(g y_{n+1}, g y_{n}\right)\right),
$$

where $h \in[0,1)$.

Set $d_{n}:=d\left(g x_{n+1}, g x_{n}\right)+d\left(g y_{n+1}, g y_{n}\right)$. Thus, the inequality (2.5) can be written as

$$
d_{n+1} \leq h d_{n} \leq h^{n+1} d_{0} \quad \text { for all } n=0,1,2, \ldots
$$

We will show that the sequences $\left\{g x_{n}\right\}$ and $\left\{g y_{n}\right\}$ are Cauchy. Without loss of generality, we may assume that $m>n$. Then, by the triangle inequality, we have

$$
\begin{aligned}
d\left(g y_{m}, g y_{n}\right)+d\left(g x_{m}, g x_{n}\right) & \leq \sum_{i=n}^{m-1} d\left(g y_{i+1}, g y_{i}\right)+d\left(g x_{i+1}, g x_{i}\right) \\
& \leq\left(\sum_{i=n}^{m-1} h^{i}\right) d_{0} \\
& =\left(\sum_{i=0}^{m-1} h^{i}-\sum_{i=0}^{n-1} h^{i}\right) d_{0} .
\end{aligned}
$$

Letting $n, m \rightarrow \infty$ in (2.6), we have

$$
\lim _{n, m \rightarrow \infty} d\left(g y_{m}, g y_{n}\right)+d\left(g x_{m}, g x_{n}\right)=0 .
$$

Consequently, $\lim _{n, m \rightarrow \infty} d\left(g x_{m}, g x_{n}\right)=0$ and $\lim _{n, m \rightarrow \infty} d\left(g y_{m}, g y_{n}\right)=0$. Hence the sequences $\left\{g x_{n}\right\}$ and $\left\{g y_{n}\right\}$ are Cauchy. Since $X$ is complete, there exist $x, y \in X$ such that

$$
\lim _{n, m \rightarrow \infty} d\left(g x_{n}, g x_{m}\right)=\lim _{n \rightarrow \infty} d\left(g x_{n}, x\right)=0
$$


and

$$
\lim _{n, m \rightarrow \infty} d\left(g y_{n}, g y_{m}\right)=\lim _{n \rightarrow \infty} d\left(g y_{n}, y\right)=0 .
$$

Thus, we obtain

$$
F\left(x_{n}, y_{n}\right)=g x_{n+1} \rightarrow x \quad \text { and } \quad F\left(y_{n}, x_{n}\right)=g y_{n+1} \rightarrow y
$$

as $n \rightarrow \infty$. Since $F$ and $g$ are $O$-compatible, we have

$$
\lim _{n \rightarrow \infty} d\left(g F\left(x_{n}, y_{n}\right), F\left(g x_{n}, g y_{n}\right)\right)=0
$$

and

$$
\lim _{n \rightarrow \infty} d\left(g F\left(y_{n}, x_{n}\right), F\left(g y_{n}, g x_{n}\right)\right)=0
$$

by (2.9).

Now, assume that (a) holds, i.e., $F$ is continuous. By taking the limit in the following inequality:

$$
d\left(g x, F\left(g x_{n}, g y_{n}\right)\right) \leq d\left(g x, g F\left(x_{n}, y_{n}\right)\right)+d\left(g F\left(x_{n}, y_{n}\right), F\left(g x_{n}, g y_{n}\right)\right)
$$

as $n \rightarrow \infty$, we obtain

$$
d(g x, F(x, y))=0
$$

by (2.7), (2.10) and the continuity of $F$ and $g$. Similarly, we can show that $d(g y, F(y, x))=0$. As a result, $F$ and $g$ have a coupled coincidence point in $X$, i.e., $g x=F(x, y)$ and $g y=F(y, x)$.

Assume that (b) holds. Since $\left\{g x_{n}\right\}$ is a non-decreasing sequence and $g x_{n} \rightarrow x$, we have $g g x_{n} \preceq g x$ for all $n \in \mathbb{N}^{*}$ by (i). Similarly, since $\left\{g y_{n}\right\}$ is a non-increasing sequence and $g y_{n} \rightarrow$ $y$, we also have $g g y_{n} \succeq g y$ for all $n \in \mathbb{N}^{*}$. Since $g$ is continuous, using (2.7), (2.10) and (2.11), we derive that

$$
\lim _{n \rightarrow \infty} d\left(g g x_{n}, g x\right)=d(g x, g x)=\lim _{n \rightarrow \infty} d\left(g F\left(x_{n}, y_{n}\right), g x\right)=\lim _{n \rightarrow \infty} d\left(F\left(g x_{n}, g y_{n}\right), g x\right)
$$

and

$$
\lim _{n \rightarrow \infty} d\left(g g y_{n}, g y\right)=d(g y, g y)=\lim _{n \rightarrow \infty} d\left(g F\left(y_{n}, x_{n}\right), g y\right)=\lim _{n \rightarrow \infty} d\left(F\left(g y_{n}, g x_{n}\right), g y\right) .
$$

By the hypothesis of the theorem, we know that

$$
H\left(\begin{array}{c}
d\left(F\left(g y_{n}, g x_{n}\right), F(y, x)\right), d\left(F\left(g x_{n}, g y_{n}\right), F(x, y)\right), \\
d\left(F\left(g x_{n}, g y_{n}\right), g g x_{n}\right)+d(F(x, y), g x), d\left(g g x_{n}, g x\right), \\
d\left(g g y_{n}, g y\right), d\left(F\left(g x_{n}, g y_{n}\right), g x\right)+d\left(F(x, y), g g x_{n}\right)
\end{array}\right) \leq 0
$$

for every $n \in \mathbb{N}^{*}$. In the inequality above, we let $n \rightarrow \infty$ and use (2.12) and (2.13) to obtain

$$
H(d(g y, F(y, x)), d(g x, F(x, y)), d(g x, F(x, y)), 0,0, d(g x, F(x, y))) \leq 0,
$$


which implies that $d(g y, F(y, x))+d(g x, F(x, y)) \leq h(0+0)=0$ by (H2) for $h \in[0,1)$. Finally, we find that $g x=F(x, y)$ and $g y=F(y, x)$ completing the proof.

Example 13 Let $(X, d, \preceq), F$ and $g$ be defined as in Example 9. We see that

- $X$ is complete and $X$ has the properties

(i) if a non-decreasing sequence $x_{n} \rightarrow x$, then $g x_{n} \preceq g x$ for all $n \in \mathbb{N}^{*}$,

(ii) if a non-increasing sequence $y_{n} \rightarrow y$, then $g y \preceq g y_{n}$ for all $n \in \mathbb{N}^{*}$.

- $F(X \times X)=\{0,1\} \subset\{0\} \cup[1 / 2,1]=g(X)$.

- $g$ is continuous and $g$ and $F$ are $O$-compatible.

- There exist $x_{0}=0$ and $y_{0}=1$ such that $g x_{0} \preceq F\left(x_{0}, y_{0}\right)$ and $g y_{0} \succeq F\left(y_{0}, x_{0}\right)$.

- $F$ has the mixed $g$-monotone property, which can be proved as follows: Let $y, x_{1}, x_{2} \in X$ such that $g x_{1} \preceq g x_{2}$. There are two cases to consider:

(1) If $g x_{1}=g x_{2}$, then $x_{1}=0$ and $x_{2}=0$ or $x_{1}, x_{2} \in[1 / 2,1]$ or $x_{1}, x_{2} \in(1, a]$ or $x_{1}, x_{2} \in(a, 2]$. Thus, $F\left(x_{1}, y\right)=0=F\left(x_{2}, y\right)$ if $y \in\{0\} \cup[1 / 2,1]$ and $x_{1}=0$ and $x_{2}=0$ or $x_{1}, x_{2} \in[1 / 2,1]$. Otherwise, $F\left(x_{1}, y\right)=1=F\left(x_{2}, y\right)$.

(2) If $g x_{1} \prec g x_{2}$, then $g x_{1}=0$ and $g x_{2}=1$, i.e., $x_{1}=0$ and $x_{2} \in[1 / 2,1]$. Thus, $F\left(x_{1}, y\right)=0=F\left(x_{2}, y\right)$ if $y \in\{0\} \cup[1 / 2,1]$ and $F\left(x_{1}, y\right)=1=F\left(x_{2}, y\right)$ if $y \in(1,2]$.

Therefore, $F$ is $g$-non-decreasing in its first argument. Similarly, it can be shown that $F$ is $g$-non-increasing in its second argument.

- There exists $H\left(t_{1}, t_{2}, t_{3}, t_{4}, t_{5}, t_{6}\right)=t_{1}-\max \left\{t_{3}, t_{4}\right\} / 2 \in \mathbb{H}$ such that (2.1) holds. To discern this, for any $x, y, u, v \in X$ with $g x \succeq g u$ and $g y \preceq g v$, we need to show that $d(F(y, x), F(v, u))=0$. Indeed,

(1) if $g x \succ g u$ and $g y \prec g v$, then $y=u=0$ and $x, v \in[1 / 2,1]$. Thus

$$
d(F(y, x), F(v, u))=d(F((0, x), F(v, 0))=d(0,0)=0 ;
$$

(2) if $g x=g u$ and $g y \prec g \nu$, then $y=0$ and $v \in[1 / 2,1]$. Either $x=u=0$, or $x, u \in[1 / 2,1]$. In any case,

$$
d(F(0, x), F(v, u))=d(0,0)=0 .
$$

Otherwise, we get

$$
d(F(0, x), F(v, u))=d(0,0)=0 .
$$

Similarly, if $g x \succ g u$ and $g y=g v$, then $d(F(y, x), F(v, u))=0$;

(3) if $g x=g u$ and $g y=g v$, then both $x, u$ are in one of the sets $\{0\},[1 / 2,1],(1, a]$ or $(a, 2]$ and both $y, v$ are also in one of the sets $\{0\},[1 / 2,1],(1, a]$ or $(a, 2]$. Thus

$$
d(F(y, x), F(v, u))=d(0,0)=0 .
$$

If $x=u=0$ or $x, u \in[1 / 2,1]$ and $y=v=0$ or $y, v \in[1 / 2,1]$, otherwise,

$$
d(F(y, x), F(v, u))=d(1,1)=0 .
$$

Therefore, all of the conditions of Theorem 12 are satisfied. Therefore, we conclude that $F$ and $g$ have a coupled coincidence point. 
Note that we cannot apply the result of Choudhury and Kundu [7], the result of Choudhury, Metiya and Kundu [25] as well as the result of Lakshmikantham and Ciric [6] to this example.

\section{Competing interests}

The authors declare that they have no competing interests.

\section{Authors' contributions}

All authors read and approved the final manuscript.

\section{Author details}

${ }^{1}$ Department of Mathematics, Cumhuriyet University, Sivas, Turkey. ${ }^{2}$ Department of Mathematics, Atilim University, Incek, Ankara 06836, Turkey. ${ }^{3}$ TED University, Ankara, Turkey.

Received: 7 September 2012 Accepted: 6 February 2013 Published: 25 February 2013

\section{References}

1. Guo, D, Lakshmikantham, V: Coupled fixed points of nonlinear operators with applications. Nonlinear Anal. 11(5), 623-632 (1987)

2. Gnana Bhaskar, T, Lakshmikantham, V: Fixed point theorems in partially ordered metric spaces and applications. Nonlinear Anal. 65, 1379-1393 (2006)

3. Ran, ACM, Reurings, MCB: A fixed point theorem in partially ordered sets and some applications to matrix equations. Proc. Am. Math. Soc. 132, 1435-1443 (2004)

4. Nieto, JJ, Rodriguez-Lopez, R: Contractive mapping theorems in partially ordered sets and applications to ordinary differential equation. Order 22, 223-239 (2005)

5. Ciric, L, Cakic, N, Rajovic, M, Ume, JS: Monotone generalized nonlinear contractions in partially ordered metric spaces. Fixed Point Theory Appl. 2008, Article ID 131294 (2008)

6. Lakshmikantham, V, Ciric, L: Coupled fixed point theorems for nonlinear contractions in partially ordered metric spaces. Nonlinear Anal. 70, 4341-4349 (2009)

7. Choudhury, BS, Kundu, A: A coupled coincidence point result in partially ordered metric spaces for compatible mappings. Nonlinear Anal. 73, 2524-2531 (2010)

8. Samet, B: Coupled fixed point theorems for a generalized Meir-Keeler contraction in partially ordered metric spaces. Nonlinear Anal. 72, 4508-4517 (2010)

9. Harjani, J, Lopez, B, Sadarangani, K: Fixed point theorems for mixed monotone operators and applications to integral equations. Nonlinear Anal. 74, 1749-1760 (2011)

10. Luong, NV, Thuan, NX: Coupled fixed points in partially ordered metric spaces and application. Nonlinear Anal. 74 983-992 (2011)

11. Luong, NV, Thuan, NX: Coupled fixed point theorems for mixed monotone mappings and an application to integral equations. Comput. Math. Appl. 62, 4238-4248 (2011)

12. Luong, NV, Thuan, NX: Coupled fixed point theorems in partially ordered metric spaces. Bull. Math. Anal. Appl. 2(4), 16-24 (2010)

13. Luong, NV, Thuan, NX: Coupled points in ordered generalized metric spaces and application to integro-differential equations. An. Stiint. Univ. Ovidius Constanta (in press)

14. Berinde, V: Generalized coupled fixed point theorems for mixed monotone mappings in partially ordered metric spaces. Nonlinear Anal. 74, 7347-7355 (2011)

15. Berinde, V: Coupled fixed point theorems for $\phi$-contractive mixed monotone mappings in partially ordered metric spaces. Nonlinear Anal. 75, 3218-3228 (2012)

16. Aydi, H, Karapınar, E, Shatanawi, W: Coupled fixed point results for $(\psi, \varphi)$-weakly contractive condition in ordered partial metric spaces. Comput. Math. Appl. 62(12), 4449-4460 (2011)

17. Karapınar, E, Luong, NV, Thuan, NX, Hai, TT: Coupled coincidence points for mixed monotone operators in partially ordered metric spaces. Arab. J. Math. 1(3), 329-339 (2012)

18. Karapınar, E: Coupled fixed point theorems for nonlinear contractions in cone metric spaces. Comput. Math. Appl. 59 3656-3668 (2010)

19. Karapınar, E: Couple fixed point on cone metric spaces. Gazi Univ. J. Sci. 24, 51-58 (2011)

20. Rhoades, BE, Jungck, G: Fixed points for set valued functions without continuity. Indian J. Pure Appl. Math. 29(3), 227-238 (1998)

21. Altun, I, Turkoglu, D: Some fixed point theorems for weakly compatible multivalued mappings satisfying an implicit relation. Filomat 22, 13-23 (2008)

22. Djoudi, A, Aliouche, A: A general common fixed point theorem for reciprocally continuous mappings satisfying an implicit relation. Aust. J. Math. Anal. Appl. 3, 1-7 (2006)

23. Popa, V: A general coincidence theorem for compatible multivalued mappings satisfying an implicit relation. Demonstr. Math. 33, 159-164 (2000)

24. Popa, V: A general fixed point theorem for four weakly compatible mappings satisfying an implicit relation. Filomat 19, 45-51 (2005)

25. Choudhury, BS, Metiya, N, Kundu, A: Coupled coincidence point theorems in ordered metric spaces. Ann. Univ. Ferrara 57, 1-16 (2011) 
doi:10.1186/1687-1812-2013-38

Cite this article as: Gülyaz et al.: A coupled coincidence point theorem in partially ordered metric spaces with an implicit relation. Fixed Point Theory and Applications 2013 2013:38.

Submit your manuscript to a SpringerOpen ${ }^{\circ}$ journal and benefit from:

- Convenient online submission

- Rigorous peer review

- Immediate publication on acceptance

- Open access: articles freely available online

- High visibility within the field

- Retaining the copyright to your article

Submit your next manuscript at $\gg$ springeropen.com 